\title{
Field performance of heat tolerant mutant rice lines generated from Oryza sativa and Oryza glaberrima
}

\author{
Paul Mbogo Kusolwa* ${ }^{1}$, Yona Neema ${ }^{1}$, Masanche Rajab ${ }^{1}$, Ashura, Luzi- Kihupi ${ }^{1}$, and Fatma \\ Sarsu $^{2}$
}

${ }^{1}$ Department of Crop Science and Production, Sokoine University of Agriculture P. O. Box 3005 Morogoro Tanzania

${ }^{2}$ Joint FAO/IAEA Division of Nuclear Techniques in Food and Agriculture, Plant Breeding and Genetics Section Vienna, Austria

\section{*Corresponding author: kusolwap@gmail.com}

\begin{abstract}
This study evaluated mutant lines developed from two cultivated species of upland rice, Oryza sativa, and Oryza glaberrima, in field experiments conducted during the hot and dry seasons of 2014/2015 in Morogoro, Tanzania. The growth yield and yield components of 34 and 14 Gamma induced mutant upland rice lines developed from O. sativa (Kihogo red) and O. glaberrima were evaluated, respectively. The mutant lines were selected based on variable expression of heat shock protein genes (HSPs) in previously conducted heat tolerance studies. The minimum and maximum temperatures and rainfall during the field performance experiment were measured between $20{ }^{\circ} \mathrm{C}$ and $35{ }^{\circ} \mathrm{C}$, and $32.7 \mathrm{~mm}$ and $155.5 \mathrm{~mm}$, respectively. The data for 12 yield and yield component parameters such as days to early and $50 \%$ flowering, days to physical maturity, plant height, number of tillers, number of panicles, spikelets, filled grains, unfilled grains and 1,000 grain weights were collected and analysed using ANOVA and Principal Component Analysis. Significant differences $(\mathrm{P} \leq 0.05)$ were obtained among the mutant lines in terms of grain yield, spikelet sterility and other variables, which were further used as criteria for selection of heat and drought tolerant rice lines. Eight heat and drought tolerant mutant rice lines with high yields (over 3.5 ton/ha) and low spikelet sterility were selected for further advancement in breeding programmes.
\end{abstract}

Key Words: Oryza sativa, Oryza glaberrima, heat tolerance, mutant lines, growth, yield and yield components.

Abbreviations: Heat tolerant (HT), Heat Shock Proteins (HSPs), Kihogo Red (KR), International Atomic Energy Agency

(IAEA)

Introduction

Rice is a staple food for more than half of the world's population, mostly living in developing countries, and is the leading cereal crop worldwide (Fageria et al., 2011). Climate changes due to global warming have negative and significant effects on rice production, particularly on its growth, development, and yield. Zhang et al. (2013) stated that extreme climate change associated with high temperature occurs more frequently and with longer duration in several rice production regions, worldwide. Increase in global temperature results in damage on growth and development of rice crops (Manneh et al., 2007).

Heat stress causes significant alterations in plant growth, development and physiological processes (Hasanuzzaman et al., 2013). High temperature has influence on almost all rice growing stages, especially, booting, flowering, and grain filling periods in many rice production regions; hence, plant growth, development, grain quality and yield are negatively affected (Ranga et al., 2011; Aghamolki et al., 2014). Zhang et al. (2013) reported that an increase in temperature of about $1-2^{\circ} \mathrm{C}$ above the optimum level during the reproductive stage results in shortening the grain filling period, with negative effects on yield and yield components in rice as well as in other cereal crops. As part of the strategies for adaptation and/or mitigation of yield reduction due to climate, concerted efforts to develop climate proof cultivars that stabilize yield have been set up.
Heat tolerant (HT) mutant rice lines were developed through mutation induction using Gamma irradiation (Yona, 2015). Subsequent mutant generations were subjected to extreme heat stress and survived plants were selected for further field evaluation. Tolerance to heat and drought stress in plants, including rice, is a complex phenomenon and controlled by multiple gene loci imparting a number of physiological and biochemical changes in plant cells (John, 2001). Plants exposed to stress parameters may survive by creating signals for changing their metabolism (John, 2001). The protection system may involve heat and drought resistance mechanisms that are associated with synthesis and accumulation of specific cell components known as heat shock proteins (HSPs) (John, 2001). The response of HSPs allows rice plants to become more tolerant to stress parameters including heat and drought (Chang et al., 2007). Several molecular plant breeding approaches have been proposed to identify the genes related to agronomic traits for rice improvement. Use of these approaches for evaluation of yield and yield component are on the verge of becoming important in terms of measuring response of a rice genotype to heat and drought stressed environments (Garge et al., 2012). The main objective of this study was to evaluate the growth, yield and yield components of the HT mutant rice lines based on their field performance tests. 


\section{Results}

Evaluation of the HT mutant rice lines: their growth performances, yield and yield components

The variables considered for evaluation of the lines generated from parental rice genotypes, cv. Kihogo Red (O. sativa), CG 14 (O. glaberrima), WAB 56_50 (O. sativa) and WAB 56_104 (O. sativa) were as follows; days to early flowering, days to $50 \%$ flowering, days to $85 \%$ physical maturity, plant height, number of tillers per plant, panicle number per plant, spikelets per panicle, filled grains per panicle, unfilled grains per panicle, 1,000 grains weight and grain yield. These variables were scored at different growth stages of the mutant lines during hot and dry field conditions. Vegetative, reproductive (booting and flowering) and maturity stages were the critical periods in this study. Collected data for lines derived from each genotype regarding the high temperature stress parameters are explained in the following sections.

Flowering rates (early and $50 \%$ ), physical maturity rates (85 $\%)$, plant height and panicle length

The mean variations of the mutant rice lines on days to early flowering, $50 \%$ days to flowering, physical maturity (days to 85 $\%)$, plant height and panicle length are given in Table 1. The data related to days to early flowering are also presented in Figure 1A. There were significant differences $(\mathrm{P}<0.05)$ among the genotypes for days to early flowering and plant height parameters (Table 1, Figure 1A). However, the difference in days to $50 \%$ flowering and days to $85 \%$ physical maturity and panicle length were not significant (Table 1). Among the lines, both CG 14_16_1 and WAB 56_50_56_2 was observed to have a short duration as ' 74 days' from sowing date to the first flowering, while KR 38_1 line had a longer period,108 days from sowing to the first emerged flower (Table 1). A shorter duration of 81 days for $50 \%$ flowering was observed for WAB 56_50_98_1 line; however, the longest duration was observed for KR 38_1 line, 125 days. In terms of physical maturity, both WAB 56_50_97_4 and WAB 56_50_127_5 lines required 98 days to reach physical maturity after sowing; however, the KR 38_1 line had a longer period of 149 days to attain $85 \%$ physical maturity (Table 1).

\section{Number of spikelets, tillers number, panicle number, filled grains and unfilled grains per plant}

There were highly significant differences $(\mathrm{P}<0.05)$ among parameters for average number of spikelets per panicle, number of tillers per plant, panicle number per plant, filled and unfilled grains per panicle per plant among all mutant lines (Figure 1B, C, $\mathrm{D}$ and $\mathrm{E})$. The highest number of spikelets per panicle was observed for CG 14_16_1 line (13 spikelets), while the lowest number was measured both in WAB 56-104 Control and CG 14_20_1 lines (nine spikelets) (Figure 1D). A high tiller number per plant was observed for WAB 56_104_150_2 line (33 tillers); however, the lowest number of tillers was identified in CG 14_16_1 line (six tillers) (Figure 1B). Similarly, the highest number of panicles was observed both for WAB 56-104 (control) and WAB 56_104_150_2 lines (27 panicles), but the lowest numbers were measured among several lines including CG 14_63_1 (Figure 1E). The highest number of filled grains per plant was observed in WAB 56_50_51_1 (759 grains) among mutant lines, while the least filled grains per plant was counted as 122 grains in WAB 56-104 control line (Figure 1C). Moreover, the lowest number of unfilled grains among all lines were measured as 74 in WAB 56_50_127_5. Data on number of tillers per plant, filled and unfilled grains in panicles per plant, number of panicles per plant and number of spikelets per panicle are presented in Figures 1B, C, D and E, respectively.

Grain yield, 1,000 grain weight, and spikelet sterility

The average data for the variations in grain yield ( $\mathrm{t} / \mathrm{ha}), 1,000$ grains weight $(\mathrm{g})$ and spikelet sterility (\%) among mutant rice lines are given in Table 2. Significant differences were observed for grain yield and spikelet sterility; however, no significant difference was identified among the mutant lines in terms of 1,000 grain weight at $\mathrm{P}<0.05$ level (Table 2). The average data related to 1,000 grain weight, grain yield and sterility rate among the analysed mutant lines are presented in Figure 2A, B and C, respectively. The highest average grain yield was observed for CG 14_63_1 and CG 14_16_1 line as 6 and 5 t/ha, respectively; while the lowest grain yield was measured as $2 \mathrm{t} / \mathrm{ha}$ both in WAB 56_50_123_3 and WAB 56_50_127_5 lines (Figure 2B). The highest 1,000 grain weight was observed for WAB 56_104_36_1 line $(33 \mathrm{~g})$, and the lowest was identified in KR 27_1 line (25g) (Figure 2A). The WAB 56_50_141_1 line however, showed the lowest sterility rate as 9\% (Figure $2 \mathrm{C}$ ).

\begin{abstract}
Analyses of growth performance yield and yield components among the WAB 56_50 mutants and control lines

Some of the comparative values for the irradiated (mutants) and non-irradiated (control) WAB 56_50 rice lines are given in Figure 3. When the mutants generated from WAB 56_50 were compared with its control lines, the average values for parameters of days to early flowering, days to $50 \%$ flowering, plant height, panicle number per plant, spikelet per panicle, filled grains and unfilled grains per panicle, 1,000 grain weight and grain yield were observed to be higher in mutant rice lines. However, the number of tillers per plant was the same, and the average values of spikelet sterility (panicle sterility) and days to physical maturity were low in mutant rice lines as compared to the control (Figure 3).
\end{abstract}

Analysis of growth performance yield and yield components among the WAB 56_104 mutants and control rice lines

Some of the comparative data for the irradiated (mutants) and non-irradiated (control) WAB 56_104 rice lines are presented in Figure 4 . When the mutants were compared with control lines, the average values for days to early flowering, days to physical maturity, plant height, panicle number per plant, filled and unfilled grains per panicle, 1,000 grain weight and grain yield were measured higher in mutant rice lines as compared to the WAB 56-104 control (Figure 4). However, the data for spikelet sterility (panicle sterility) and days to physical maturity were high in non-mutant rice genotype as compared to HT mutant rice lines, except for the number of days to $50 \%$ flowering and spikelets/panicle were observed as the same among HT mutant and control lines (Figure 4).

\section{Analysis of growth performance yield and yield components among the CG 14 mutants and control rice} lines

The comparative values for the irradiated mutants and nonirradiated control CG 14 rice lines are given in Figure 5. The average values for parameters of days to early flowering, days to $50 \%$ flowering, days to physical maturity, plant height, spikelets/panicle, filled grains, bird loss (\%) and grain yield were observed to be higher in CG derived mutant lines as compared to non-mutant control genotype. The unfilled grains/panicle and spikelet sterility parameters were low in mutant rice lines when compared with its control. However, the panicle number per plant and 1,000-grain weight parameters were observed to be the same both in mutant lines and control rice genotypes (Figure 5).

\section{Analysis of growth performance yield and yield components among the Kihogo red (KR) mutants and control rice lines}

The comparative values for the irradiated and non-irradiated Kihogo red $(\mathrm{KR})$ rice lines are presented in Figure 6. The average values for the parameters of plant height, filled grains per panicle, 
Table 1. The mean variations of the mutant rice lines on days to early flowering, $50 \%$ days to flowering, physical maturity (days to $85 \%$ ), plant height and panicle length.

\begin{tabular}{|c|c|c|c|c|c|}
\hline Rice line & $\begin{array}{c}\text { Days } \\
\text { to early flowering }\end{array}$ & $\begin{array}{c}50 \% \\
\text { days to flowering }\end{array}$ & $\begin{array}{c}\text { Days to } 85 \% \\
\text { Maturity }\end{array}$ & $\begin{array}{l}\text { Plant } \\
\text { height } \\
(\mathrm{cm})\end{array}$ & $\begin{array}{l}\text { Panicle length } \\
(\mathrm{cm})\end{array}$ \\
\hline KR 27_1 & $95 \mathrm{de}$ & $104 c$ & $147 d$ & 130gh & 23abcd \\
\hline KR 38_1 & $108 \mathrm{ef}$ & $125 d$ & 149d & $131 \mathrm{~g}$ & $21 \mathrm{abc}$ \\
\hline CG 14_16_1 & $74 a$ & $85 a$ & $108 \mathrm{abc}$ & 104abcde & $21 \mathrm{abc}$ \\
\hline CG 14_20_1 & $77 \mathrm{abc}$ & $82 \mathrm{a}$ & $104 \mathrm{abc}$ & $105 \mathrm{abcde}$ & 23abcd \\
\hline CG 14_58_1 & $81 \mathrm{~cd}$ & $89 \mathrm{ab}$ & $109 \mathrm{abc}$ & $113 \mathrm{cdef}$ & $21 \mathrm{abc}$ \\
\hline CG 14_61_3 & 79abcd & $87 \mathrm{ab}$ & $110 \mathrm{abc}$ & $114 \mathrm{ef}$ & $35 \mathrm{bcd}$ \\
\hline CG 14_63_1 & $77 \mathrm{abc}$ & $88 \mathrm{ab}$ & $100 \mathrm{ab}$ & $100 \mathrm{ab}$ & $20 \mathrm{ab}$ \\
\hline CG 14_63_2 & $77 \mathrm{abc}$ & $82 a$ & $107 \mathrm{abc}$ & $95 a$ & 22abcd \\
\hline WAB 56_104_36_1 & $81 \mathrm{~cd}$ & $89 \mathrm{ab}$ & $109 \mathrm{abc}$ & $114 \mathrm{ef}$ & $20 \mathrm{ab}$ \\
\hline WAB 56_104_141_1 & $81 \mathrm{bcd}$ & $97 \mathrm{~b}$ & $108 \mathrm{abc}$ & $109 \mathrm{bcdef}$ & $25 \mathrm{abcd}$ \\
\hline WAB 56_104_141_2 & $78 \mathrm{abcd}$ & $85 a$ & $106 a b c$ & $110 \mathrm{bcdef}$ & $21 \mathrm{abc}$ \\
\hline WAB 56_104_141_3 & $75 \mathrm{abc}$ & $83 a$ & $107 \mathrm{abc}$ & 109bcdef & 24abcd \\
\hline WAB 56_104_150_2 & $77 \mathrm{abc}$ & $84 a$ & $107 \mathrm{abc}$ & 108bcdef & 24abcd \\
\hline WAB 56_50_51_1 & $76 a b c$ & $80 a$ & $106 a b c$ & $101 \mathrm{abc}$ & $36 \mathrm{~d}$ \\
\hline WAB 56_50_56_1 & $80 \mathrm{abcd}$ & $89 \mathrm{ab}$ & $108 \mathrm{abc}$ & $113 \mathrm{def}$ & $20 \mathrm{ab}$ \\
\hline WAB 56_50_56_2 & $74 a$ & $82 \mathrm{a}$ & $111 \mathrm{bc}$ & $99 \mathrm{ab}$ & $21 \mathrm{ab}$ \\
\hline WAB 56_50_74_1 & $77 \mathrm{abc}$ & $85 a$ & $110 \mathrm{abc}$ & $118 f$ & $25 \mathrm{abcd}$ \\
\hline WAB 56_50_82_1 & $77 \mathrm{abc}$ & $83 a$ & $111 b c$ & 107bcdef & $21 \mathrm{ab}$ \\
\hline WAB 56_50_85_2 & 79abcd & $85 a$ & $105 \mathrm{abc}$ & 106abcde & 23abcd \\
\hline WAB 56_50_85_3 & $76 a b c$ & $86 a b$ & $111 \mathrm{bc}$ & $114 \mathrm{ef}$ & $22 \mathrm{abc}$ \\
\hline WAB 56_50_97_2 & 76abc & $84 a$ & $113 c$ & 106abcde & 23abcd \\
\hline WAB 56_50_97_3 & $77 \mathrm{abc}$ & $84 a$ & $110 \mathrm{abc}$ & 110bcdef & $21 \mathrm{ab}$ \\
\hline WAB 56_50_97_4 & $75 \mathrm{ab}$ & $87 \mathrm{ab}$ & $98 \mathrm{a}$ & 103 abcde & $21 \mathrm{ab}$ \\
\hline WAB 56_50_98_1 & $75 \mathrm{ab}$ & $81 \mathrm{a}$ & $111 \mathrm{bc}$ & 104abcde & $21 \mathrm{ab}$ \\
\hline WAB 56_50_98_3 & $77 \mathrm{abc}$ & $91 \mathrm{ab}$ & $108 \mathrm{abc}$ & 108bcdef & 22abcd \\
\hline WAB 56_50_123_1 & $75 \mathrm{abc}$ & $84 a$ & $106 a b c$ & 103 abcde & 22abcd \\
\hline WAB 56_50_123_2 & $75 \mathrm{ab}$ & $79 \mathrm{a}$ & $104 \mathrm{abc}$ & 104abcde & $22 \mathrm{abc}$ \\
\hline WAB 56_50_123_3 & $84 d$ & $86 a b$ & $111 \mathrm{bc}$ & 108bcdef & $20 \mathrm{ab}$ \\
\hline WAB 56_50_127_3 & $78 \mathrm{abc}$ & $82 a$ & $108 \mathrm{abc}$ & 104abcde & 22abcd \\
\hline WAB 56_50_127_5 & $80 \mathrm{bcd}$ & $85 a$ & $98 \mathrm{a}$ & 108bcdef & $21 \mathrm{ab}$ \\
\hline WAB 56_50_135_1 & $75 \mathrm{abc}$ & $81 \mathrm{a}$ & $109 \mathrm{abc}$ & $101 \mathrm{abcd}$ & $21 \mathrm{ab}$ \\
\hline WAB 56_50_141_1 & $80 \mathrm{abcd}$ & $85 a$ & $105 \mathrm{abc}$ & $112 \mathrm{cdef}$ & $25 \mathrm{abcd}$ \\
\hline WAB 56_50_141_2 & 79abcd & $85 a$ & 109abc & 104abcde & $20 \mathrm{a}$ \\
\hline WAB 56_50_152_3 & $81 \mathrm{~cd}$ & $86 a b$ & $108 \mathrm{abc}$ & 103abcde & $36 \mathrm{~cd}$ \\
\hline KR control & $109 \mathrm{f}$ & $122 \mathrm{~b}$ & $148 \mathrm{~d}$ & $127 \mathrm{fg}$ & $109 \mathrm{f}$ \\
\hline CG 14 Control & $80 \mathrm{bcd}$ & $91 \mathrm{ab}$ & $106 a b c$ & $113 \mathrm{cdef}$ & $21 \mathrm{abc}$ \\
\hline WAB 56-104 Control & 78abcd & $84 a$ & $107 \mathrm{abc}$ & 110bcdef & 23abcd \\
\hline WAB 56-50 Control & $76 a b c$ & $83 a$ & $106 a b c$ & 103 abcde & $22 \mathrm{abc}$ \\
\hline Grand mean & 78 & 85 & 107 & 107 & 23 \\
\hline S.E & 3.106 & 6.04 & 6.131 & 6 & 7.3 \\
\hline $\mathrm{CV}$ & 4.0 & 7.1 & 5.7 & 5.6 & 31.6 \\
\hline
\end{tabular}

*Figures followed by the same letter (s) in columns are not significantly different at $\mathrm{P}<0.05$ according to DMRT.

1,000 grain weight and grain yield in mutant rice lines were high, when compared with non-irradiated control genotype.

In contrast, days to early flowering, days to $50 \%$ flowering, panicle length, spikelets per panicle, unfilled grains per panicle, bird loss and spikelet sterility parameters were observed to be low in mutant rice lines when compared with the control lines. The number of tillers per plant, panicle number per plant and days to physical maturity values; however, were the same among irradiated mutants and non-irradiated control lines (Figure 6).

\section{Principal Component Analysis}

A Principal Component Analysis (PCA) was performed to compare all the genotypes with their controls and to identify the major traits which contribute to the variations observed for heat tolerance in the lines tested (Figure 8). The first component accounts for $47.76 \%$ of the variation and the second $20.68 \%$, The cumulative variance accounting for $68.46 \%$ of the total variation. The PCA plot is given in Figure 8; and as it can be seen that most genotypes cluster are together. The outliers are: the KR lines (KR control and its mutant lines KR27_1 and KR38_1), WAB56_50_74_1, WAB56_104_36_1 and CG14-63-1. The PC1 axis separates the three $\mathrm{KR}$ genotypes from the rest of genotypes (mainly yield component traits), whereas WAB56_50_74_1, WAB56_104_36_1 and CG14_63_1 are separated from the More detailed comparisons of mutants with their respective parents are made in individual trait analyses (ANOVA). grown in several highly populated countries including China, India, Indonesia, Malaysia, Philippines, Taiwan and etc. Unlike Oryza sativa rice species, Oryza glaberrima is grown in limited areas in the world. However, this African rice species contains many unique and useful traits such as heat and drought tolerance, pest and disease resistance, weed competitiveness, and the ability to grow under low input conditions (Sarla and Mallikarjuna, 2005). Furthermore, Oryza glaberrima is a potential source of genes to enhance eating, cooking, and milling properties of rice grain.

\section{1 | Page}



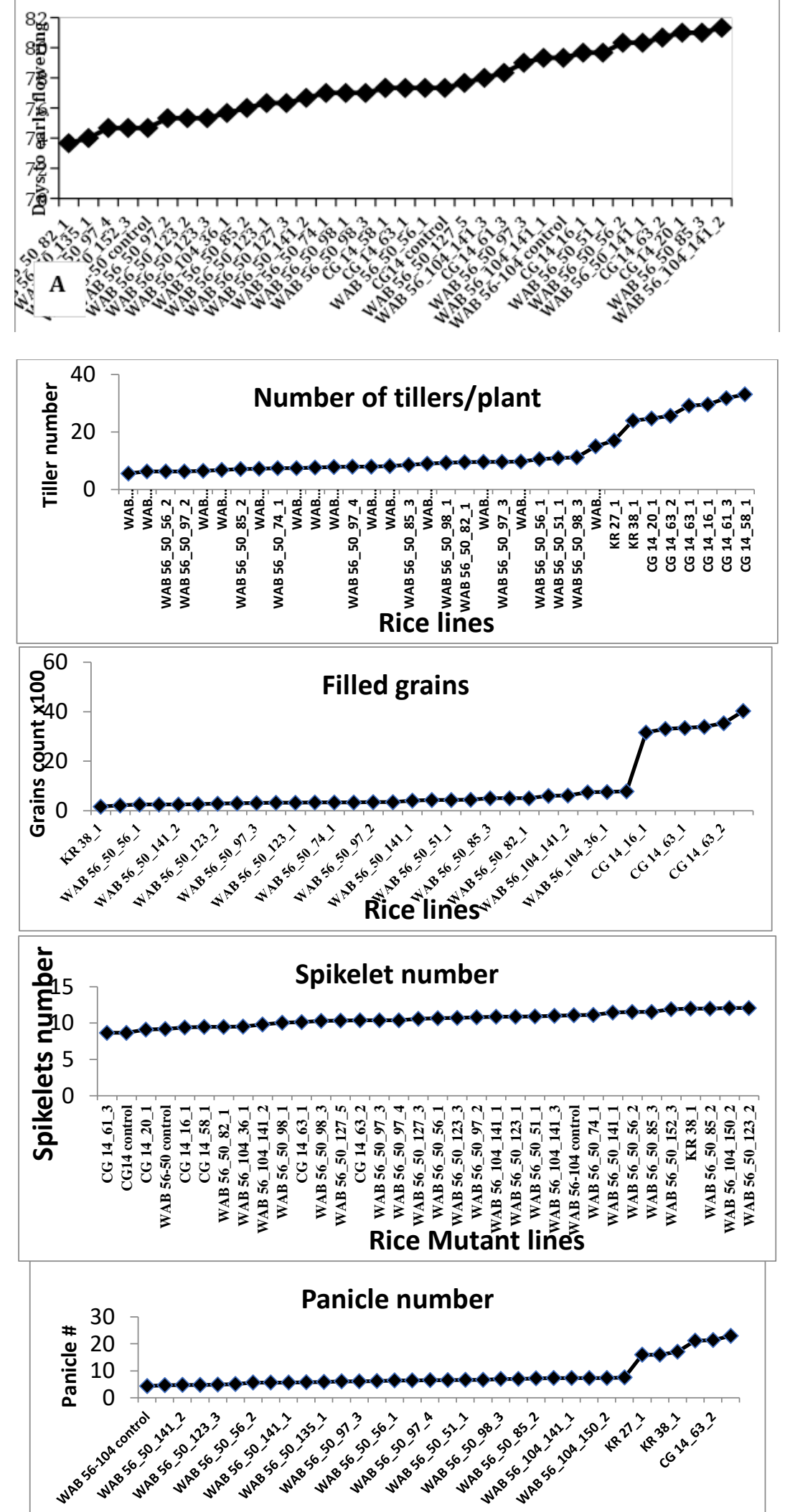

\section{Rice Mutant lines}

Fig 1. Identified data for some of the growth components of the evaluated mutant rice lines (A) Number of days to $50 \%$ flowering, (B) The average number of tillers, (C) filled grains, (D) spikelets, and (E) panicles of rice mutant lines ordered from the lowest to the highest. 
Table 2. The mean summary for variations of mutant rice lines on grain yield ( $\mathrm{t} / \mathrm{ha}), 1,000$ grains weight (g), spikelet sterility and bird loss percentage.

\begin{tabular}{|c|c|c|c|}
\hline Rice line & Grain yield (t/ha) & 1,000 grain wt. (g) & Spikeletsterility (\%) \\
\hline KR 271 & $3.4 \mathrm{a}$ & $25 a^{*}$ & $50.7 \mathrm{a}$ \\
\hline KR 38_1 & $6.5 \mathrm{a}$ & $31 \mathrm{~b}$ & $43.6 \mathrm{a}$ \\
\hline CG 14_16_1 & $7 e$ & $28 \mathrm{abc}$ & $21 \mathrm{abc}$ \\
\hline CG 14_20_1 & $3 a b c$ & 29abcd & $26 \mathrm{bc}$ \\
\hline CG 14_58_1 & $7 e$ & $28 \mathrm{abc}$ & $18 \mathrm{abc}$ \\
\hline CG 14_61_3 & $5 \mathrm{~cd}$ & 30abcd & $14 \mathrm{abc}$ \\
\hline CG 14_63_1 & $8 \mathrm{e}$ & 29abcd & $22 \mathrm{abc}$ \\
\hline CG 14_63_2 & 6de & $28 \mathrm{abc}$ & $19 \mathrm{abc}$ \\
\hline WAB 56_104_36_1 & $3 a b c$ & $33 d$ & $14 \mathrm{abc}$ \\
\hline WAB56_104_141_1 & $3 a b c$ & $30 \mathrm{abcd}$ & $13 \mathrm{ab}$ \\
\hline WAB 56_104_141_2 & $4 \mathrm{bc}$ & $30 \mathrm{abcd}$ & $14 \mathrm{abc}$ \\
\hline WAB 56_104_141_3 & $3 a b$ & 30abcd & $18 \mathrm{abc}$ \\
\hline WAB 56_104_150_2 & $2 \mathrm{ab}$ & $29 \mathrm{abc}$ & $11 \mathrm{a}$ \\
\hline WAB 56_50_51_1 & $3 a b c$ & $31 \mathrm{bcd}$ & $14 \mathrm{abc}$ \\
\hline WAB 56_50_56_1 & $2 \mathrm{ab}$ & $30 \mathrm{abcd}$ & $15 \mathrm{abc}$ \\
\hline WAB 56_50_56_2 & $3 \mathrm{ab}$ & $26 a$ & $17 \mathrm{abc}$ \\
\hline WAB 56_50_74_1 & $3 a b$ & $31 \mathrm{~cd}$ & $13 \mathrm{ab}$ \\
\hline WAB 56_50_82_1 & $3 \mathrm{ab}$ & $30 \mathrm{abcd}$ & $16 \mathrm{abc}$ \\
\hline WAB 56_50_85_2 & $3 a b c$ & $29 \mathrm{abc}$ & $19 \mathrm{abc}$ \\
\hline WAB 56_50_85_3 & $3 a b c$ & 29abcd & $17 \mathrm{abc}$ \\
\hline WAB 56_50_97_2 & $3 \mathrm{ab}$ & $30 \mathrm{abcd}$ & $20 \mathrm{abc}$ \\
\hline WAB 56_50_97_3 & $2 \mathrm{ab}$ & $28 \mathrm{abc}$ & $17 \mathrm{abc}$ \\
\hline WAB 56_50_97_4 & $3 a b$ & 29abcd & $23 \mathrm{abc}$ \\
\hline WAB 56_50_98_1 & $2 \mathrm{ab}$ & $27 \mathrm{abc}$ & $28 c$ \\
\hline WAB 56_50_98_3 & $3 a b$ & $30 \mathrm{bcd}$ & $19 \mathrm{abc}$ \\
\hline WAB 56_50_123_1 & $3 \mathrm{ab}$ & $31 \mathrm{bcd}$ & $20 \mathrm{abc}$ \\
\hline WAB 56_50_123_2 & $3 a b$ & $31 \mathrm{bcd}$ & 19abc \\
\hline WAB 56_50_123_3 & $2 \mathrm{a}$ & 30abcd & $15 \mathrm{abc}$ \\
\hline WAB 56_50_127_3 & $2 \mathrm{ab}$ & 29abcd & $21 \mathrm{abc}$ \\
\hline WAB 56_50_127_5 & $2 \mathrm{a}$ & $27 \mathrm{abc}$ & $22 \mathrm{abc}$ \\
\hline WAB 56_50_135_1 & $2 \mathrm{ab}$ & $28 \mathrm{abc}$ & $20 \mathrm{abc}$ \\
\hline WAB 56_50_141_1 & $3 a b c$ & $31 \mathrm{bcd}$ & $9 \mathrm{a}$ \\
\hline WAB 56_50_141_2 & $2 \mathrm{ab}$ & 29abcd & $26 \mathrm{bc}$ \\
\hline WAB 56_50_152_3 & $2 \mathrm{ab}$ & $27 \mathrm{ab}$ & $11 \mathrm{a}$ \\
\hline KR control & $3.7 \mathrm{a}$ & $27 \mathrm{a}$ & $48.9 \mathrm{a}$ \\
\hline CG14 Control & 6de & 29abcd & $17 \mathrm{abc}$ \\
\hline WAB 56_104 Control & $2 \mathrm{ab}$ & $31 \mathrm{~cd}$ & $12 \mathrm{ab}$ \\
\hline WAB 56_50 Control & $3 \mathrm{ab}$ & 28abc & $19 \mathrm{abc}$ \\
\hline Grand mean & 3 & 29 & 18 \\
\hline S.E & 0.92 & 1.95 & 7.12 \\
\hline $\mathrm{CV}$ & 28.4 & 6.6 & 40.3 \\
\hline
\end{tabular}

Oryza glaberrima and Oryza sativa breeding programmes resulted in several positively inbreed lines including traits such as adaptation to difficult West African conditions with high yield, resistance to drought, and pest and diseases (Sarla and Mallikarjuna, 2005). The main hindrance in the use of Oryza glaberrima as a germplasm is its incompatibility in pollination with Oryza sativa; however, this obstacle has been overcome by generating fertile progeny from Oryza sativa $\times$ Oryza glaberrima

crosses. Therefore, new inbreed lines presented a broader range of germplasm for rice breeders (Dingkuhn et al., 1998).

Of the 34 mutant lines used in this study, 28 were generated from Oryza sativa (two from KR, five from WAB 56_104 and 21 from WAB 56_50 genotypes) and six from Oryza glaberrima (from CR 14 genotype) (Table 3). Comparison of the 12 yield and yield component parameters of these mutant lines revealed that Oryza glaberrima derived CR 14 genotyped mutant lines showed better performance than the Oryza sativa derived KR genotyped mutant lines, and almost the same performance with WAB 56_104 and WAB 56_50 genotyped mutant lines in terms of days to early and $50 \%$ flowering, days to physical maturity, plant height, filled grains, 1,000-grain weight and grain yield parameters (Figure 3, 4, 5 and 6). These mutant lines from Oryza glaberrima present a unique opportunity to African breeders as novel germplasm for future breeding programmes. Interestingly, the PCA plot (Figure 8) did not separate the $O$. oryza genotypes from the O. glaberimaa genotypes (they clustered together), however, the tall KR (O. Sativa) genotypes were separated (Fig. 8).

\section{Discussion}

Differences between Oryza sativa and Oryza glaberrima Two main rice species, Oryza glaberrima and Oryza sativa, and their four different genotypes, cv. Kihogo Red, WAB 56_50, WAB 56_104 (Oryza sativa) and CG 14 (Oryza glaberrima) were used as plant materials in the study. 


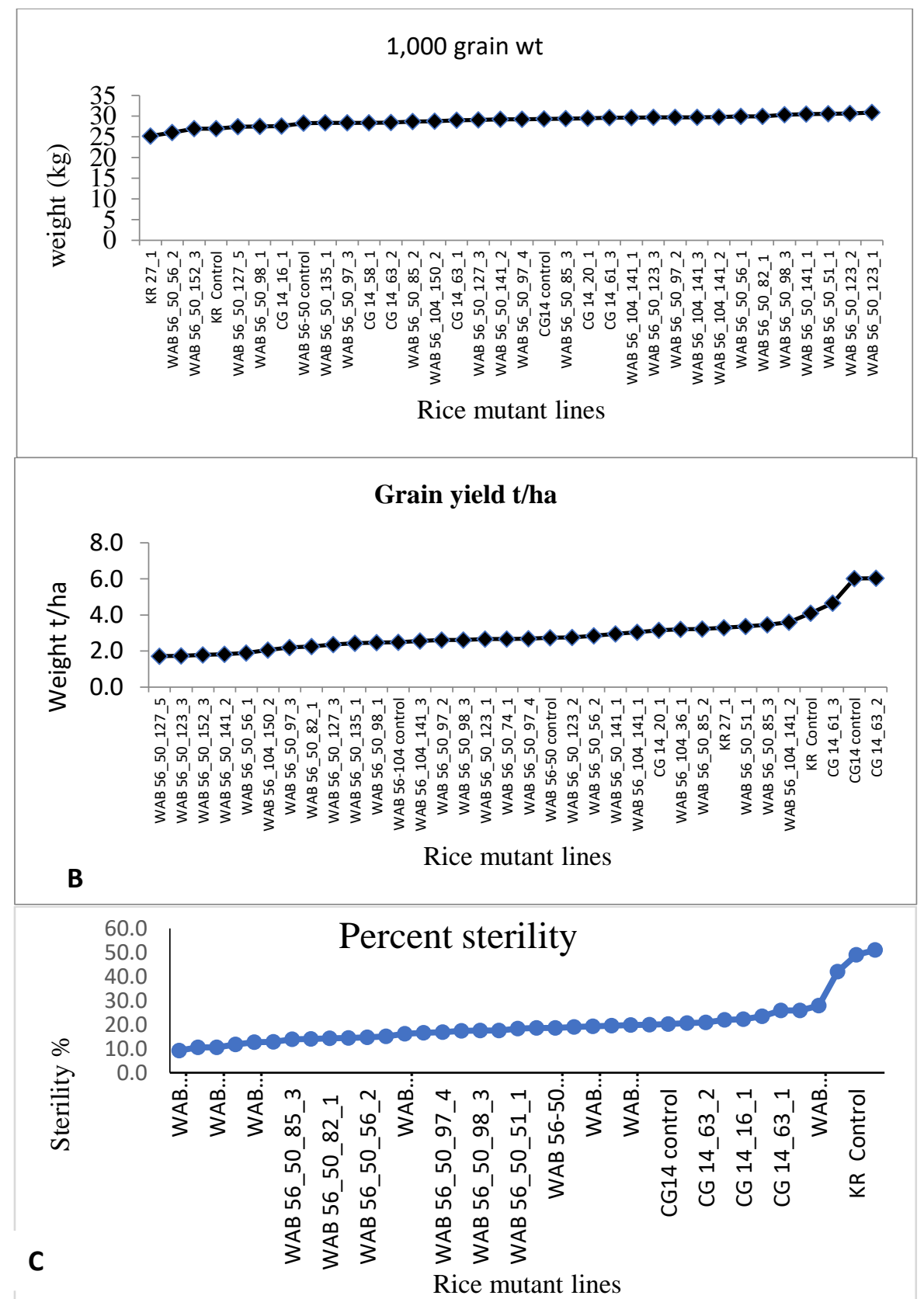

Fig 2. Yield and yield components of the evaluated mutant rice lines (A) 1,000 grain weight (g), (B) grain yield (t/ha), and (C) spikelet sterility of rice mutant lines.

\section{Effects of induced mutations on growth performance of the HT mutant rice lines}

The evaluation of the effects of induction mutation on growth performance of the HT mutant rice lines was accomplished by assessing the parameters of plant height, panicle length, days to early flowering, days to $50 \%$ flowering and days to $85 \%$

physical maturity. Days to early flowering and plant height parameters revealed significant differences; however, no significant difference was observed for panicle length, days to 50 $\%$ flowering and days to $85 \%$ physical maturity. The induced mutations may have positive or negative effects on plant growth characteristics. The results indicate that the mutant lines had better field performances than their parental lines in terms of growth. The mutant rice lines flowered earlier than the control lines indicating that they are adapted to short growing periods and this adaptation may assist in overcoming high temperature stress. Thus, the flowering and fertilization processes will not be affected by high temperature (Matsui et al., 2001). During the reproductive stage, high temperatures negatively affect flowering, pollination, grain filling and pollen production leading to spikelet sterility and low grain yield (Matsui et al., 2001; Ranga et al., 2011; Aghamolki et al., 2014). Jiang-lin et al. (2011) and Norvie et al. (2014) stated that the plant growth parameters of heat-susceptible-rice-genotypes can be negatively affected by high temperature at all growth stages as compared to HT rice. High temperature stress (above optimum levels) is also expected to affect development and all growth stages of the heat susceptible genotypes, and to decrease grain quality and yield (Shah et al., 2011). Therefore, use of the HT rice may help to improve rice production. 
Table 3. HT mutant upland rice lines with modified expression of HSPs.

\begin{tabular}{|c|c|c|}
\hline $\begin{array}{l}\text { Sample } \\
\text { ID }\end{array}$ & Mutant rice line & Species \\
\hline 1 & KR 27_1 & $O$ sativa \\
\hline 2 & KR 38_1 & O sativa \\
\hline 3 & CG 14_16_1 & O. glaberima \\
\hline 4 & CG 14_20_1 & O. glaberima \\
\hline 5 & CG 14_58_1 & O. glaberima \\
\hline 6 & CG 14_61_3 & O. glaberima \\
\hline 7 & CG 14_63_1 & O. glaberima \\
\hline 8 & CG 14_63_2 & O. glaberima \\
\hline 9 & WAB 56_104_36_1 & O sativa \\
\hline 10 & WAB 56_104_141_1 & $O$ sativa \\
\hline 11 & WAB 56_104_141_2 & O sativa \\
\hline 12 & WAB 56_104_141_3 & O sativa \\
\hline 13 & WAB 56_104_150_2 & O sativa \\
\hline 14 & WAB 56_50_51_1 & O sativa \\
\hline 15 & WAB 56_50_56_1 & O sativa \\
\hline 16 & WAB 56_50_56_2 & O sativa \\
\hline 17 & WAB 56_50_74_1 & O sativa \\
\hline 18 & WAB 56_50_82_1 & O sativa \\
\hline 19 & WAB 56_50_85_2 & O sativa \\
\hline 20 & WAB 56_50_85_3 & O sativa \\
\hline 21 & WAB 56_50_97_2 & O sativa \\
\hline 22 & WAB 56_50_97_3 & O sativa \\
\hline 23 & WAB 56_50_97_4 & O sativa \\
\hline 24 & WAB 56_50_98_1 & O sativa \\
\hline 25 & WAB 56_50_98_3 & O sativa \\
\hline 26 & WAB 56_50_123_1 & O sativa \\
\hline 27 & WAB 56_50_123_2 & O sativa \\
\hline 28 & WAB 56_50_123_3 & $O$ sativa \\
\hline 29 & WAB 56_50_127_3 & O sativa \\
\hline 30 & WAB 56_50_127_5 & O sativa \\
\hline 31 & WAB 56_50_135_1 & O sativa \\
\hline 32 & WAB 56_50_141_1 & O sativa \\
\hline 33 & WAB 56_50_141_2 & O sativa \\
\hline 34 & WAB 56_50_152_3 & O sativa \\
\hline 35 & KR Control & O sativa \\
\hline 36 & CG 14 Control & O. glaberima \\
\hline 37 & $\begin{array}{c}\text { WAB 56_104 } \\
\text { Control }\end{array}$ & O sativa \\
\hline 38 & WAB 56_56 Control & $O$ sativa \\
\hline
\end{tabular}

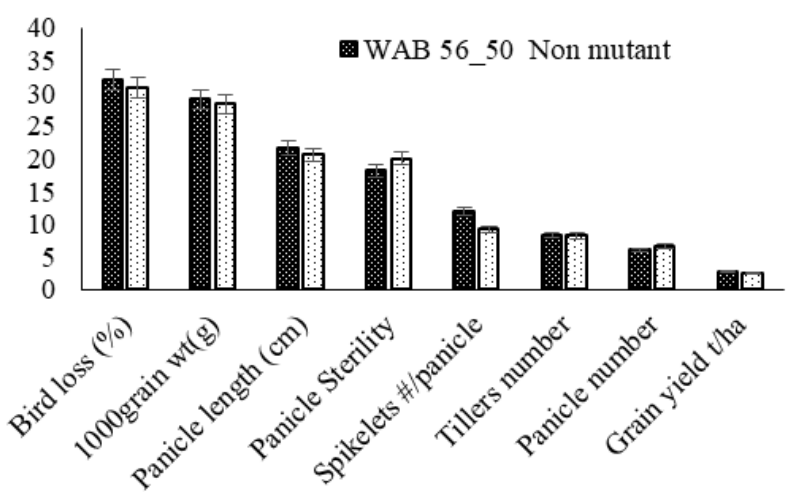

Fig 3. Comparison of growth yield and yield component values of mutant lines with their non-mutant control rice line both generated from the WAB 56_50 genotype (the $\mathrm{Y}$ axis is the proportion of significant mean performance of each variable derived from analysis of variance).
Effects of induced mutations on number of tillers, panicle number, number of spikelets, filled grains and grain yield in mutant rice lines

The current study revealed that there were significant differences (at $\mathrm{P}<0.05$ level) among the parameters: number of spikelets per panicle, number of tillers/plant, panicle number/plant, filled and unfilled grains/panicle/plant among lines (Table 2).

The results of HT mutant rice lines indicated that such mutations were associated with increased number of tillers, number of panicles, number of spikelets and number of filled grains/plant. The Oryza glaberrima lines seemed to perform

better than Oryza sativa; however, Oryza glaberrima derived genotypes used in mutation had undesirable logging characteristics beside their higher yields. Therefore, we discarded them in the selection process.

These findings were in agreement with Cheema and Atta (2003), where an increase in the number of reproductive tillers/plants also resulted in an increase in panicle number/plant and spikelets/plant, and thus grain yield. Furthermore, De Datta (1975) findings confirmed that tillering was a major factor determining rice yield. Surek and Beser (2003) reported that there was a positive relation between grain yield/plant and yield components; total spikelets/panicle, filled grains/panicle and 1,000 grain weight. An increase in these yield components also increased grain yield of the mutant rice lines as well as their productivity under heat and drought stresses. Surek and Beser (2003) also suggested that individual yield components might contribute valuable information in rice breeding for yield. In general, an increase in yield components also resulted in increase for grain yield among all the HT mutants as compared to control rice lines.

The effects of induced mutations on grains yield, 1,000 grain weight and percentage spikelet sterility in mutant upland rice lines

The results showed that there were significant differences among all rice lines in terms of grain yield and spikelet sterility; however, no significant difference was observed among lines for 1,000 grain weight at $\mathrm{P}<0.05$ level (Table 2). Surek and Beser (2003) stated that effects of mutations may contribute alterations in tye number of tillers/plant, number of spikelets/panicle, number of panicles/plant and filled grains; hence, they were directly associated with higher grain yield. Similarly, our study revealed that the grain yield was higher in all HT mutant rice lines than the parental control genotypes. These outputs indicate that heat tolerant mutant rice lines are better able to tolerate heat stress and they show higher performance in terms of production capacity. The spikelet sterility rates identified for both Oryza sativa and Oryza glaberrima driven mutants were observed to be very low among all evaluated HT mutant rice lines as compared to controls (Table 3). The main reasons to obtain these results are their ability to sustain plant growth even under heat and drought stress and to produce more filled grains than unfilled grains. Hence, the selected mutant rice lines are highly tolerant to heat and drought stress. Indeed, Porter and Semenov (2005) and Mahmood et al. (2010) reported that both grain number and grain yield in many temperate cereal crops, and as well as in rice, seemed to be affected by heat stress, and the decline in grain yield was directly proportional with increasing temperatures during flowering and grain filling stage among heat susceptible rice genotypes. The high temperature $\left(35^{\circ} \mathrm{C}\right)$ during panicle development, heading and flowering stages also cause a high percentage of spikelet sterility in heat susceptible rice varieties (Shah et al., 2011; Wopereis et al., 2008; Sheehy et al., 2005). 


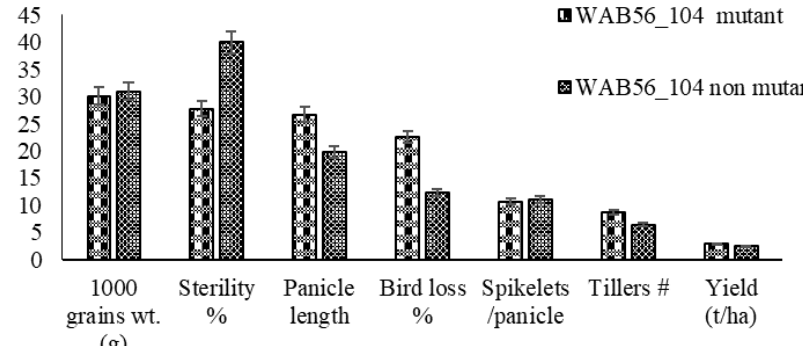

(g)

Figure 4. Comparison of yield and yield component values of mutant lines with their non-mutant control rice line both generated from WAB 56_104 genotype (the Y axis is the proportion of significant mean performance of each variable derived from analysis of variance).

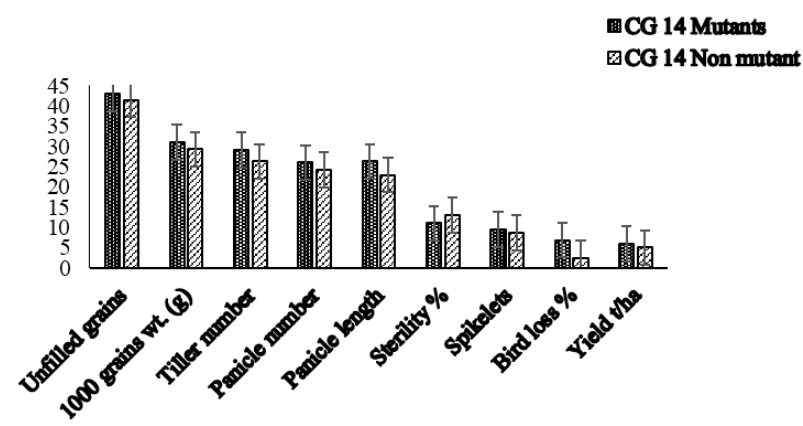

Figure 5. Comparison of yield and yield component values of mutant rice lines with their non-mutant control rice lines both generated from CG 14 rice genotype (the $\mathrm{Y}$ axis is the proportion of significant mean performance of each variable derived from analysis of variance).

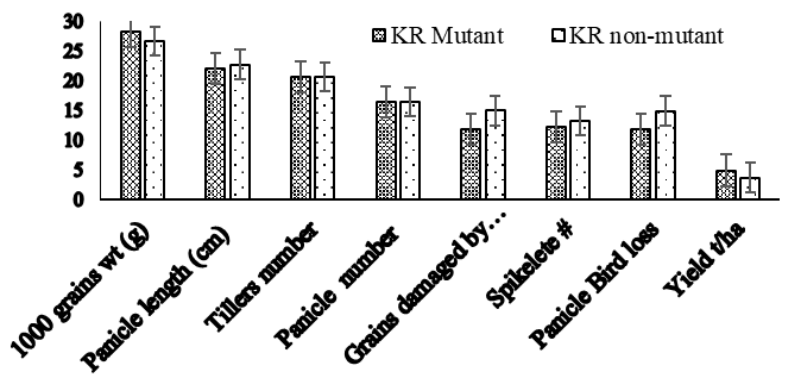

Figure 6. Comparison of yield and yield component values of mutant rice lines with their non-mutant control line both generated from KR rice genotype (the $\mathrm{Y}$ axis is the proportion of significant mean performance of each variable derived from analysis of variance).

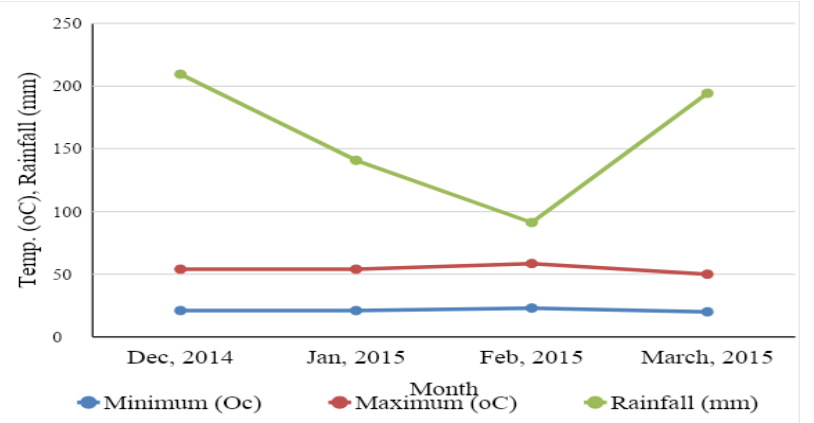

Figure 7. Climate trends of four months in SUA, Morogoro 2014/2015. Source; Tanzania Meteorological Agency, MorogoroWeather Station, 2014/2015.
High temperature during booting and flowering stages lead to abnormal pollen development (Jiang-lin et al., 2011) and increase pollen sterility (Matsui et al., 2001), respectively. Thus, it leads to a serious panicle infertility and decrease grain yield in heat susceptible rice varieties. The current results indicated that there were no significant differences in 1,000 grain weight at 5\% statistical interval among all lines including Oryza sativa and Oryza glaberrima driven mutant rice lines. Even though the mutant lines generated from CG 14 genotype of Oryza glaberrima presented similar data; however, there were significant differences among the mutant lines generated from WAB 56_50, WAB 56_104 and Kihogo red (KR) genotypes of Oryza sativa. These results indicated that grain sizes were not affected by the high temperature stress among all mutant rice lines.

The selected HT induced mutants from both Oryza sativa and Oryza glaberrima rice species also showed promising performances in the field trials. Therefore, induced mutations have a high potential to protecting the yield under heat stress conditions.

\section{Material and Methods}

\section{Plant material}

Two main rice species, Oryza glaberrima and Oryza sativa, and their four different genotypes, cv. Kihogo Red, WAB 56_50, WAB 56_104 (Oryza sativa) and CG 14 (Oryza glaberrima) were used as plant materials in the study. Uniform sized seeds (about $500 \mathrm{gr}$ corresponding to 20,000 seeds for each genotype) with $12 \%$ moisture content of Oryza sativa Kihogo red, WAB 56_50 and WAB 56_104 genotypes were irradiated with $150 \mathrm{~Gy}$ dose, and Oryza glaberimma CG 14 genotype was also irradiated with $250 \mathrm{~Gy}$ dose (a higher dose is required for O. glaberimma as seeds were harder, lower water content than O. sativa) at FAO/IAEA Plant Breeding and Genetics Laboratories at Seibersdorf and shipped back to Tanzania. After the irradiation process, the seeds were immediately planted for generation of $\mathrm{M}_{1}$ plants. The $\mathrm{M}_{1}$ generation was grown in the experimental field of the Sokoine University Farming area in Morogoro. Following the $\mathrm{M}_{1}$ stage, single spikes were harvested from each plant for $\mathrm{M}_{2}$ generation, and selection of the best lines from $\mathrm{M}_{1}$ to $\mathrm{M}_{2}$ was carried out based on individual plants. Among the 20,000 seedlings, a total of $160 \mathrm{M}_{3}$ mutant lines from each genotype, which were previously subjected to the heat stress screening in growth chamber in seedling stage at $45^{\circ} \mathrm{C}$, were identified. The surviving individual plants were selected following a complete growth recovery in the screen house after the heat shock; maintained for seed production and were considered as putative tolerant lines at the seedling stage.

\section{Experimental design and field studies}

The selected $\mathrm{M}_{4}$ lines were studied in a randomized block design (RCBD) with three replications to evaluate the performance of 34 heat tolerant mutant upland rice lines. The best lines were compared with their parents in order to select the best improved mutants. Seeds of best mutants were collected individually from each generation. The standard rice agriculture practices were followed through all production stages.

Field experiments were conducted in 2014/2015 period starting from December 2014 to February 2015 during 'vuli', which was the short rainfall and hot season before the long rainfall season called 'Masika'. The experiment was designed at the rice experimental plots of the Department of Crop Science and Production of Sokoine University of Agriculture, Morogoro, Tanzania, located at latitude $6^{\circ} 50^{\prime} 55^{\prime \prime} \mathrm{S}$ latitude and $37^{\circ} 39^{\prime} 22^{\prime \prime}$ $\mathrm{E}$ longitude. The daily average maximum and minimum temperatures and rainfalls were recorded about three 


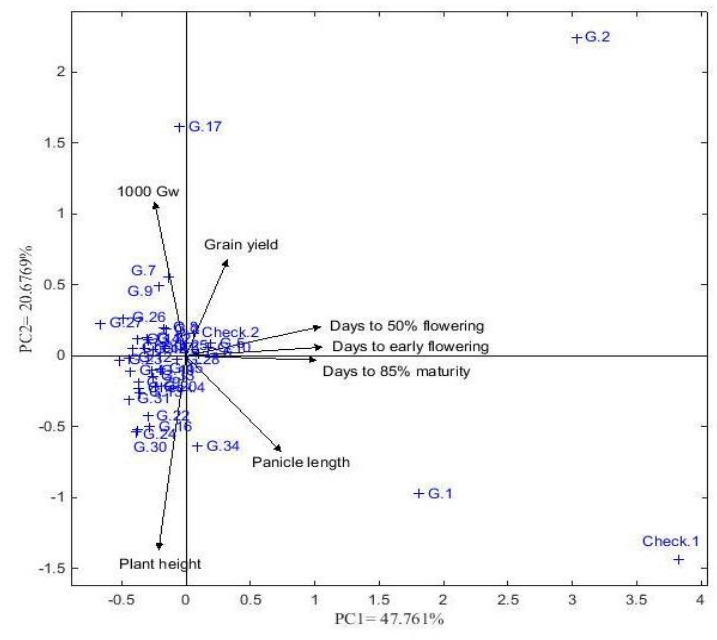

Figure 8. PCA plot of PC1 and PC2 showing the direction of main influencing traits $(1,000$ grain weight, grain yield, days to $50 \%$ flowering, days to early flowering, days to $85 \%$ maturity, panicle length and plant height) on all genotypes tested

months. These values were between $20^{\circ} \mathrm{C}$ and $35.5^{\circ} \mathrm{C}$ temperature, and $32.7 \mathrm{~mm}$ and $155.5 \mathrm{~mm}$ rainfall in December 2014, January, February and March 2015, respectively. A total rainfall and average minimum and maximum temperature for the above-mentioned month periods was presented in Figure 7. Performance of 34 heat tolerant mutant upland rice lines were evaluated under natural and uncontrolled heat and scarce rainfall stress parameters in field conditions (Table 3). These lines were planted as single rows in 15 hill plots $(20 \times 20 \mathrm{~cm})$ and each mutant rice line was treated as one plot $(0.2 \mathrm{~m} \mathrm{x} 3 \mathrm{~m})$.

\section{Data collection}

Data for growth, yield and yield components were measured for the following parameters as described; number of reproductive tillers per plant at the maximum tilling stage, days to early and $50 \%$ flowering (days at which the first flowers appeared and the day when at least half of the rice plants exerted a fully opened panicle per plot), days to $85 \%$ physical maturity (counted from the day of sowing until more than $85 \%$ of rice grain turned from green to brown), plant height $(\mathrm{cm})$ from at least five plants per line (measured at maturity stage, from the collar of the plant to the longest leaf and averages calculated), panicle number (the number of panicles per plant per plot), number of spikelets per panicle in each treatment, panicle length, number of spikelets per plant and spikelet sterility percentage (obtained through a relationship between the number of unfilled grains and total number of grains per panicle). The supplementary tables were also provided regarding ANOVA results of each variables and for each genotype of mutant lines identified (Supplementary Tables 1-15). The plots were manually harvested at physiological maturity using sickles when $90 \%$ of the panicles turned brown. The panicles were sun dried for a period of $3-4$ days to reduce moisture content to approximately $12-13 \%$. Yield data were determined based on weight of 1,000 grains, and grain yield per plot were measured using a seed counter, and then weighed using a sensitive digital scale. Grain yield per plot was recorded by weighing the filled grain per plant in per plot, and then were converted to grain yields ( $\mathrm{t} / \mathrm{ha}$ ). Apart from several yield and yield components, bird loss was also recorded as an additional parameter.

\section{Data analysis}

Analysis of variance (ANOVA) was carried out on all traits (see Tables 1 and 2). In addition, a principal component analysis (PCA) was performed (Figure 8) on the measured variables, based on Pearson correlation matrix and Euclidean distances. Eigenvectors generated by the PCA were used to identify parameters that best differentiated the genotypes in each experiment.

\section{Conclusion}

Rice is a staple food and energy source for over half of the world's population. Climate changes, particularly, high temperature may have negative impacts on rice production via resulting in deleterious effects on almost all rice growth stages. Hence, developing high temperature tolerant cultivars are utmost importance. The HT rice mutant lines were previously developed through mutation induction using Gamma irradiation. The current study; however, evaluated these lines in the field conditions. Several mutant lines representing two main rice species; Oryza sativa (grown worldwide), and Oryza glaberrima, which was grown in limited areas but contained many unique and useful traits including heat and drought tolerance, were analysed. Significant data among the comparison of the mutants and parental lines were obtained in terms of growth performance, yield and yield component parameters. Regarding the growth performance, days to early flowering and plant height parameters showed significant differences. Regarding the yield and yield component parameters; however, grain yield, spikelet sterility, number of spikelets per panicle, number of tillers/plants, panicle number/plant, filled and unfilled grains/panicle/plant revealed significant differences. Hence, these variables were proven to be used as criteria for selecting heat and drought tolerant rice lines. The selected HT induced mutations from both Oryza sativa and Oryza glaberrima rice species showed promising performances in field experiments. Eight heat and drought tolerant mutant rice lines showing high yields (over 3.5 ton/ha) were selected for further advancement in breeding programmes. Therefore, the induced mutation technique has a potent effect on generating rice lines to protect and even increase yield under high temperature, heat and drought stress conditions.

\section{Acknowledgements}

We are grateful to the International Atomic Energy Agency (IAEA), Joint FAO/IAE Division for financial and technical support this investigation.

\section{References}

Aghamolki MTK, Yusop MK, Oad FC, ZakikhaniHawa H. Jaafar ZS, Kharidah SM, Hanafi MM (2014) Response of yield and morphological characteristic of rice cultivars to heat stress at different growth stages. International Journal of Biological, Biomolecular, Agricultural, Food and Biotechnological Engineering 8(2):98-100.

Chang PFL, Jinn TL, Huang WK, Chen Y, Chang HM, Wang CW (2007) Induction of a cDNA clone from rice encoding a class II small heat shock protein by heat stress, mechanical injury, and salicylic acid. Plant Sci. 172:64-75.

Cheema AA, Atta MB (2003) Radio sensitivity studies in basmati rice. Pak J Bot. 35(2):197-207.

De Datta SK (1975) Upland rice around the world. In major research in upland rice, IRRI, Los Banos, (1975), Philippines.

Dingkuhn M, Jones MP, Johnson DE, Sow A (1998) Growth and yield potential of oryza sativa and oryza glaberrima upland rice cultivars and their interspecific progenies. Field Crops Res. 57(1):57-69.

Fageria NK, Moreira A, Coelho AM (2011) Yield and yield components of upland rice as influenced by nitrogen sources. J Plant Nutr. 34:361-370.

\section{7 | Page}


Garge D, Sareen S, Dalal S, Tiwari R, Singh R (2012) Heat shock protein-based SNP marker for terminal heat stress in wheat (Triticum aestivum L.). Aust J of Crop Sci. 6(11):1516-1521.

Hasanuzzaman M, Nahar K, Fujita M (ed) (2013) Extreme temperatures, oxidative stress and antioxidant defence in plants. In: (Edited Vahdati K. \& Leslie C.) abiotic stress-plant responses and applications in agriculture. In tech; Rijeka, pp 169-205, (2013), Croatia.

Jiang-lin L, Hong-yu Z, Xue-lian S, Ping-an Z, Ying-jin H (2011) Identification on heat tolerance in backcross recombinant lines and screening of backcross intogression lines with heat tolerance at milky stage in rice. Rice Sci. 18(4):1-8.

John JB (2001) Identification of genetic diversity and mutations in higher plant acquired thermo tolerance. Physiol Plant. 112(2):167-170.

Mahmood S, Wahid A, Javed F, Basra SMA (2010) Heat stress effects on forage quality characteristics of maize (Zea mays) cultivars. Int J Agric Biol. 12:701-706.

Manneh B, Kiepe P, Sie M, Ndjiondjop M, Drame NK, Traore K, Rodenburg J, Somado EA, Narteh L, Youm O, Diagne A, Futakuchi K (2007) Exploiting partnerships in research and development to help african rice farmers cope with climate variability. ICRISAT. Africa rice center (WARDA). Cotonou 4 (1), (2007), Benin.

Matsui T, Omasa K, Horie T (2001) The difference in sterility due to high temperature during the flowering period among Japonica rice varieties. Plant Prod Sci. 4:90-93.

Norvie LM, Leslie AFL, Luvina BM, Corazon CC (2014) Germplasm innovation of heat tolerance in rice for irrigated lowland conditions in the philippines. Rice Sci. 21(3):162-169.

Porter JR, and Semenov MA (2005) Crop responses to climatic variation. Philos Trans R Soc B Biol Sci. 360:2021-2035.

Ranga SVK, Jagadishb QM, Zhoua PQ, Craufurdc S, Heuer B (2011) Effect of high temperature and water stress on pollen germination and spikelet fertility in rice. Environ Exp Bot. 70:58-65.
Sarla N, and Mallikarjuna SBP (2005) Oryza glaberrima: a source for the improvement of Oryza sativa. Curr Sci. 89(6):955-963. Shah F, Huang J, Cui K, Nie L, Shah T, Chen C, Wang K (2011) Impact of high-temperature stress on rice plant and its traits related to tolerance. J Agric Sci. 149(5):545-556.

Sheehy JE, Elmido A, Centeno G, Pablico P (2005) Searching for new plants for climate change. J Agric Meteo. 60:463-468.

Surek H, Beser N (2003) Selection for grain yield and yield components in early generations for temperate rice. Philipp J Crop Sci. 28(3):3-15.

Wopereis MCS, Defoer T, Idinoba P, Diack S, Dugue M J (2008) Participatory learning and action research for integrated rice management (IRM) in inland valleys of sub-saharan africa: Technical manual. WARDA training series. Africa rice centre pp 128 (2008), Benin.

Yona N (2015) Genetic characterization of heat tolerant (HT) upland mutant rice selected from rice genotypes. MSc Dissertation, Sokoine University of Agriculture, pp 111 (2015), Tanzania.

Zhang Y, Tang Q, Peng S, Zou Y, Chen S, Shi W, Qin J, Laza CR (2013) Effects of high night temperature on yield and agronomic traits of irrigated rice under field chamber system condition. Aust J of Crop Sci. 7(1):7-13. 